\title{
NOTES ON THE PUMPING ENGINES AT THE LINCOLN WATER WORKS.
}

\author{
BY Mr. HENRY TEAGUE, ExGINEER OF THE WoRKs.
}

On the occasion of the visit of the Members to the Lincoln Water Works at the Summer Meeting of the Institution in 1885 (Proceedings 1885, page 446), a good deal of interest was manifested in regard to yarious mechanical details in connection with the Pumping Engines, respecting which numerous enquiries were made both at the time and subsequently. Having been requested to furnish some particulars respecting these details and the reasons for their adoption and the experience of their practical working, the author has much pleasure in complying with the request by offering the following notes.

Sims' Compound Engine.-The first pumping engine was erected in 1848. This is the original compound engine first constructed on Sims' plan, having the high and low pressure cylinders continuous with cach other, as shown in Fig. 1, Plate 14. It had been made in $\mathbf{1 8 3 6}$ by Messrs. Harvey, Hayle Foundry, Cornwall ; and had been working on two Cornish mines before its removal to Lincoln. A 25-inch cylinder is fixed on the top of a 50-inch cylinder, and the two pistons are on one piston-rod, the space between them being at all times open to the condenser. The length of stroke is 8 feet, and the 12-inch plunger-pump at the other end of the beam has a stroke of 7 feet. The valve arrangements are the same as those of an ordinary singlecylinder Cornish engine.

Balance Valve.-The pump works against a pressure equal to 350 feet head of water, the city drawing its supply direct from the pumping main. When a main pipe burst or a hydrant was opened quickly, it was found that the catch-pins came down too heavily 
on the spring-beams. To avoid this, the author in the autumn of 1848 fixed in the main delivery pipe from the pump a balance valve of the construction shown in Fig. 10, Plate 16. The valve $D$ is a flat disc on a vertical spindle, closing upon a seating below; and is held open by two spiral springs $S$, pressing against a crosshead $H$ upon the spindle above the stuffing-box. The upper end of the spindle is screwed, and fitted with a nut $\mathrm{N}$ above the crosshead $\mathrm{H}$, by means of which the compression of the springs is adjusted to the required amount for holding the valve open to the extent desired, against the current of water flowing downwards through it from the pump, as indicated by the arrows. Any increase in the velocity of flow tends to close the valve. On the top of the spindle is a second nut $M$, which can be adjusted to drop upon the crossbar B, so as either to limit the valve to partial closing, when it is desired to let the engine continue working on, or else to allow the valve to close entirely; in the latter case the lower nut $\mathrm{N}$ can be screwed up against the underside of the crossbar $B$ for holding the valve down securely on its seat. The valve-spindle being of brass and only $1 \frac{1}{2}$ inches diameter, there is but little friction in the stuffingbox; and the valve has consequently been found to be far more sensitive than the double-beat and treble-beat valves usually adopted, which by their friction on their centre pole or guide pin are caused to be much too slow in action.

Exhaust and Equilibrium Valve Catches.-To be as safe as possible, and hold the engine at either end of the stroke whenever the catch-pins strike the spring-beams, catches were at the same time applied to the shafts of the exhaust and equilibrium valves, as shown in Fig. 11, Plate 17. This view illustrates the case in which either the steam valve or the top delivery clack of the pump has failed to close as promptly as it ought to do, and the pressure of steam has consequently been in excess of the load in the indoor or downstroke of the pistons; the upper tappet ' $T$ on the plug rod $P$ has consequently depressed the handle of the exhaust shaft $\mathrm{E}$ so far that the bottom catch $\mathrm{C}$ has caught; and it will so remain, holding the exhaust valve shut, until released by the engine-man. The steam catch is liberated by a rod and lever fixed on the exhaust shaft; 
consequently its liberation is prevented, and the steam valve also is held shut, until the bottom catch $\mathbf{C}$ is released. The top catch on the equilibrium shaft $Q$ acts in a similar manner whenever there is a decrease of load in the upstroke of the pistons; the lower tappet on the plug rod then lifts the handle of the shaft $Q$ so high that the cateh becomes caught, and holds the equilibrium valve shut until released by hand. These catches the author has found invaluable, the engine being caught and held stationary after the next single outdoor or indoor stroke, until they are released by the engine-man; and ever since 1848 he has applied them to all the pumping engines he has had erected in different towns. Instead of letting the engine make the next single stroke before stopping, there is no difficulty in arranging catches to hold the engine instantly (Proceedings 1853, page 112), and it was so intended at first; but on further consideration it was thought no damage would be done by the engine making the next single stroke in the opposite direction, and this view has held good in practice, the present simple method above described having been found to be all that is required. The opening of the valves is effected in the ordinary way by weights.

Combined Bucket and Plunger Pump.-In 1852 a small auxiliary engine was erected, and the question arose as to the best kind of pump to be adopted. After some consideration a combined bucket

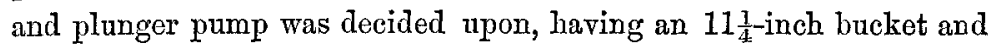
an 8-inch plunger, with a stroke of $2 \frac{1}{2}$ feet. In working it was found that, in consequence of the contracted water-way through the bucket clack, it made a great noise both in opening and in closing; and the author therefore determined that, if he ever had to fix another combined pump, he would substitute a piston instead of the bucket, and provide a clear water-way both in the suction clack and in the delivery clack. The idea of the combined bucket and plunger pump he believes to have originated with Smeaton, though claimed by many others subsequently; indeed even as late as three years after the author's own application of it at Lincoln it was twice announced as a new idea. Naturally to an observer watching the delivery head of an ordinary bucket-pump, when tho 
large wooden pump-rods were in use, it required no very great stretch of imagination to apply the plunger in combination with the bucket, seeing that in the descent of the rod a volume of water equal to its own bulk was displaced.

Combined Piston and Plunger Pump.--In 1862, being in want of more pumping power, it occurred to the author that, as the city draws its supply direct from the main and only tho surplus is delivered into the reservoir, a double-acting fly-wheel engine would not be so much affected by a sudden withdrawal of water as the ordinary single-acting beam engine. A 36-inch single-cylinder doubleacting engine with 8 feet stroke, and with six double-beat valves for the steam distribution-two steam, two expansion, and two exhaust,-was accordingly erected, as shown in Fig. 3, Plate 15, having been made by Messrs. Williams, Perran Foundry, Cornwall. To this engine was applied a combined piston and plunger pump, shown in Figs. 4 and 5, possibly the first of the kind, having a 123-inch piston and a 9-inch plunger, with a stroke of 7 feet; the valves were Harvey and West's double-beat clacks of 14 inches diameter (Proceedings 1858, Plate 61, Fig. 1). The fly-wheel was placed intermediate between the pump and the beam centre, the crank having a stroke of $4 \frac{3}{4}$ feet. The action of this engine was satisfactory, with the exception of the heavy beating of a single-flap clack in a 15-inch bucket lift with a head of 20 feet for raising the water on to the filter beds.

Relief or Break Clack.-For obviating the annoyance of this concussion, without incurring the expense of a double-beat clack for such a situation, the author began to devise some simple remedy. A 4-inch break-valve he was aware had been applied by Mr. Gribble at the beginning of the present century to a 16-inch exhaust valve in a pumping engine with 91-inch cylinder at the United Mines, Cornwall; it was quite a success, and is sketched from memory in Figs. 6 and 7, Plate 16, showing both valves closed. The long slots in the lugs on the large valve allowed the small valve to open first, which was found a great benefit in relieving the load on the large valve. On the other hand the anthor knew that the pyramid of 
clacks, sketched from memory in Fig. 8, Plate 16, had practically failed; and no better result had attended the treble clack (Proceedings 1858, Plate 61, Fig. 3) designed by Mr. R. Jenkyn, of Copperhouse Foundry, Hayle, in which three separate rings were hung one upon another, but all hinged on the same side. In regard to the last, it occurred to the author that the reason of the failure lay in the three clacks being all hung on the same side; and that, had they been hung alternately on opposite sides, the desired aim of obviating concussion would have been accomplished. To test the correctness of this view, the 15-inch clack was removed early in 1863 , and one-third of its area was cut out in the centre of the flap; the aperture so made was covered with a supplementary leather clack hinged upon the main clack at the edge opposite to the main hinge, as shown in Figs. 12 and 13, Plate 17. By this means the concussion was so completcly prevented, that on placing the hand or ear in contact with the clack box not the least tremor or sound was perceptible, and the time of closing could not be detected. The leather of the small supplementary clack continued in constant action for seven years before requiring to be changed, and that of the main clack for thirteen years. In 1866, when the Harvey and West double-beat valves in the 14-inch main pump began to leak, the author replaced them with leather breals-clacks of this construction, whereby the action of the pump was greatly improved, as shown by the two pairs of diagrams in Figs. 14 and 15, Plate 17, which were both taken under similar circumstances when the pump was travelling at 160 feet per minute. These diagrams were taken with a McNaught indicator having a spring of $10 \mathrm{lbs}$. per inch of range. Fig. 14 shows the vacuum above the clacks, which at the commencement of the stroke is $5 \frac{1}{2}$ lbs. per square inch for the breakclack, as shown by the full line, and $7 \mathrm{lbs}$. for the double-beat valve, as shown by the dotted line; Fig. 15 shows the vacuum below the clacks, which began at 4 lbs, per square incl in each case. The suction pipe is 13 inches diameter, and runs 40 feet horizontally from the pump before dipping into the tank, in which the water. level at the time of taking the diagrams was 6 feet below the bottom clack. In trking a number of diagrams similar to those 
shown in Figs. 14 and 15, it was found that scarcely any two were exactly alike. This was attributed in most instances to the undulatory motion of the water in the tank from which it was being pumped; the tank was 70 feet long by 40 feet wide, and the undulation was sufficient at times to raise the indicated line above the atmospheric line at the finish, as shown by the thin full line at $A$ in Fig. 15. In some pumps with a vacuum of about $7 \mathrm{lbs}$. per square inch or 16 feet head of water at the commencement of the upstroke, the indicated line has been raised several feet above the atmospheric line at the finish. To obviate this evil with a long horizontal suction-pipe, it occurred to the author in 1852 to interpose at the foot of the pump a large air-tight box or vacuum vessel, for the long horizontal suction-pipe to deliver into; the vessel contains sufficient vacant space to spare for taking up the fluctuations of the water, which are thereby prevented from affecting the working of the pump. This addition has been found to answer the purpose thoroughly, the pumps working with the greatest ease when so supplemented. The author was led to the introduction of the vacuum vessel in consequence of being consulted about a 4-inch hand-pump, to which had been laid a 2-inch suction-pipe of 480 yards length, with a vertical dip of 8 feet at the well end; although the pipe was filled at starting, the pump would not draw any water, until he added a vacuum vessel of six times the cubic content of the pump. This rendered the action so easy that a boy could work it. On the construction of the Gainsborough Water Works in 1866, the vacuum vessel was called into requisition for a 12-inch plunger-pump, supplied from the river by a 10-inch suction-pipe of 1000 feet length; the pipe runs 425 feet horizontally from the river, then rises 16 feet, and thence runs 575 feet horizontally to the pump. In several other instances the vacuum vessel has been applied with equally good results.

The break-clacks, Figs. 12 and 13, work incessantly for five years without changing a leather, and without showing the least sign of leakage, under 350 feet head of water or 150 lbs. per square inch; and there is not the slightest concussion, the time of closing not being perceptible. For a velocity of 160 feet per minute of the pump the 
author has found the weight of the flap should be about 2 lbs. per square inch. On the top of the second or supplementary clack a third of still smaller diameter can be applied, and even a fourth or more, hung alternately on opposite sides.

In 1884, when it was found that still further pumping power was required, the author decided to revert to the Cornish pumping engine, notwithstanding the consideration which had previously led him to choose a double-acting fly-wheel engine in 1862-namely that the city draws its supply direct from the main. For the experience gained from the working of the Cornish pumping engines which he had erected in the interval at Grantham, Maidstone, and other places, had convinced him that the cost of coals and repairs had been reduced in some instances to as low as lonly one-sixth of the annual expenditure pertaining to rotatory pumping engines previously in use there. The new Cornish pumping engine accordingly procured from Messrs. Harvey, Hayle Foundry, was started in March 1885, and is shown in Fig. 2, Plate 14; its action has been all that could be desired, while the saving of coal has been no less than 543 tons in ten months. The cylinder is 58 inches diameter and $9 \frac{1}{2}$ feet stroke; the plunger is 18 inches diameter and 8 feet stroke, with three of Harvey and West's double-beat clacks. The main girders and spring-beams are of wrought-iron, with india-rubber buffers to receive the catch-pins. Every joint in the cylinder, and in the steam, feed, and other pipes, and also in the pump work, is faced; and all are bolted together, iron to iron, with only thin paint between. The shafts of the exhaust and equilibrium valves are fitted with the useful catches previously mentioned. In the equilibrium pipe is placed a check throttle-valve V, Fig. 11, Plate 17, which is adjusted by a hand-wheel $W$ according to the proper load from time to time upon the engine (Proceedings 1853, page 111, and Plate 25, Fig. 4). This keeps the speed of the engine under perfeet control in the outdoor or upstroke of the piston, against any ordinary fluctuations in the load. The valve is opened wider whenever the load is permanently increased, and is closed further if the load is reduced; the range of load is from 220 to 350 feet head 
of water. The delivery main from the pump is fitted with Husband's balance valve, Fig. 9, Plate 16, which is a double-beat valve loaded with an adjustable dead-weight; but owing to the friction of the stuffing-box round the plunger of 8 inches diameter attached to the valve, this is not found to be so sensitive as the balance valve previously adopted by the author, which is adjusted by springs, as already described.

Coal Consumption.-The Sims' compound engine and the 36-inch double-acting fly-wheel engine are found to consume about $4 \mathrm{lbs}$. of coal por horse-power per hour for actual work done. The 58-inch Cornish engine consumes $3 \cdot 14$ lbs. per horse-power per hour in the ordinary course of working, without any special arrangements being made for a test. The coal used is the Nottinghamshire and Derbyshire slack; its evaporative duty the author believes does not much exceed $7 \mathrm{lbs}$. of water per lb. of slack, and varies between that amount and only two-thirds as much; its efficiency is therefore not to be compared with that of Welsh coal.

About $1 \frac{1}{2}$ miles west of the city, and a mile west of the filter beds and pumping station, is the impounding reservoir of 23 acres area, which forms an ornamental lake in the grounds of Hartsholme Hall. On the Cross o' Cliff hill, $1 \frac{1}{4}$ mile south of the pumping station and near the county asylum, is an open service reservoir holding $1 \frac{1}{2}$ million gallons. On the opposite hill, 2 miles north of the pumping station and near the cathedral, is another open service reservoir holding 800,000 gallons, into which the pumping main delivers over a standpipe. When the consumption below hill is greater than the quantity pumped by the main engines, no water will rise over the standpipe; this occurs not only in extremely hot weather, but also on very cold days, when taps are left running to waste in order to prevent freezing. A $6 \mathrm{HP}$. gas engine is therefore provided for pumping back over the standpipe out of the reservoir, to supply the upper part of the houses situated on the top of the hill; and there is a back-pressure valve on the crown of the hill, for preventing the water so pumped back from flowing down the main below hill. 
Sewage Pumping Engines.-At the sewage pumping station, situated in the valley about half a mile east of the city, the sewage is pumped up and delivered on to the corporation farm by a pair of vertical compound engines made by Messrs. Hathorn Davey and Co., Leeds. The high-pressure cylinders are 15 inches diameter, and the low-pressure 30 inches diameter, the length of stroke being 5 feet. The plunger pumps are 22 inches diameter with 5 feet stroke. The feature that recommended these engines was the differential gear for catching the engine in case of the fouling of the clacks or bursting of a main.

\section{Discussion.}

Mr. William B. Bryan, engineer of the East London Water Works, said that he had under his care at Old Ford the first Cornish engine ever made for waterworks purposes. It had now been at work forty-nine years, and not a single improvement as regarded efficiency had been made upon it in any subsequent Cornish engines for waterworks, including the new Cornish pumping engine described in the paper and started in 1885 at the Lincoln Water Works. He had himself thought that Cornish engines had become things of the past for waterworks purposes. Having under his care Cornish engines capable of lifting 108 million gallons daily, he was in a position to say that they were sources of very great anxiety. It was true they worked very well, magnificently in some respects; but the engine-driver was never allowed to leave his post. The work was very economical; nominally $21 \mathrm{lbs}$. of feed-water per horse-power per hour was the average quantity used, working the week through. From some tests lately taken he had fotnd 320 heat-units per minute per horse-power were passing away from the hot-well of the condenser. The duty was very deceptive, because while pumping 
into mains the pressure would often fall 30 or 40 per cent. The load was precisely the same for a high lift as for a low lift; consequently the nominal consumption of $21 \mathrm{lbs}$. of feed-water, if estimated in the work actually done, might become 28 or 30 lbs. per horse-power per hour. The intermittent action of the flow was also very trying to the joints in the water-pipes. No matter how carefully it was endeavoured to prevent this by means of air-vessels or standpipes, it still would occur. With regard to the suction-boxes upon the long suction-mains, referred to in the paper (page 129), he knew of some suction-pipes 4000 feet long, which were without suction-boxes, and they worked very well; the pumps were three-throw pumps drawing direct from the pipes, and to his own knowledge there had been no difficulty within the last ten years. It appeared to him that one of the most perfect pumping engines for pumping direct into the mains was the high-duty Worthington engine, in which the steam used was always exactly proportional to the weight of water to be lifted. For lifing water from deep wells, he thought the compound direct-acting engine of Mr. Davey was also one of the best. The Cornish engine had no doubt done very fine duty; but he was much astonished to find that a new one had been put to work in the year 1885 .

With regard to the combined bucket and plunger pump, with which it was mentioned in the paper (page 126) that a difficulty had been experienced in getting sufficient water-way through the bucket clack, he had himself found that if a double-beat valve was used on the bucket, instead of a clack, there was not the slightest difficulty. Under his own care two compound engines with bucket and plunger pumps, built by Messrs. Simpson ten years ago, were working splendidly at a very high piston-speed, and no such difficulty as that experienced by the author had ever occurred. Of the valves shown in the drawings, he thought some were rather crude. The doublebeat valve and the four-beat valve, used by Messrs. Harvey and West, and invented by Mr. Husband or Mr. West, acted most perfectly in all the engines under his own charge, and no difficulty had ever occurred; he considered them the best kind of valve for very large pumping engines. 
Mr. J. W. Restler, engineer of the Southwark and Vaushall Water Works, had thirteen Cornish engines with cylinders varying from 36 to 112 inches diameter and working against heads varying from 80 to 350 feet. Where the pressures remained constant, they were of course working at their best; but in the case of eight of the engines, the head against which they had to pump raried about 80 feet in the 24 hours, owing to the exigencies of the supply; and as the engines had to be weighted sufficiently to overcome the maximum head, there must in such cases be always a considerable loss of efficiency. They were thus he thought unsuited for districts where the supply was taken direct from the pumping mains, in which the draught and consequently the pressure were continually fluctuating. To keep the pressure constant, it was necessary that the speed of the engines should be continually varying; and in order to accomplish this object in the most economical manner, he was now having fitted to the expansion gear of two pairs of 600 H.P. direct-acting compound engines a governor actuated by the pressure in the main, which would automatically vary the degree of expansion in exact proportion to the work the engine was at the moment called upon to perform. These engines were working with a steam pressure of 100 lbs. per square inch, and were taking over the work formerly done by a pair of 80 -inch Cornish beam-engines working with a boiler pressure of $40 \mathrm{lbs}$. The duty obtained from the compound engines showed a saving equal to at least 50 per cent. over the Cornish. The satisfactory nature of these results had led him to design for the new works now under construction a pair of quadruple-expansion engines, which were intended to work with a steam pressure of 200 lbs: per square inch. They were to draw the supply for their pumps directly from a main in which the pressure varied from 50 to 200 feet head; and to deliver against a head varying from 250 to 400 feet. This wide range of work would be automatically adjusted by a governor, which would be actuated by the pressure in both suction and delivery mains, and which would act on the expansion gear in the same manner as the governor used for the compound engines. In both cases ordinary high-speed governors driven from the crank-shafts were also fitted 
to act upon a throttle-valve, so as to check the engines in the event of accident to either main.

Mr. Edmund L. Morris, engine superintendent of the New River Water Works, observed that the plan of fitting safety-catches to the exhaust and equilibrium valves, for preventing the engine from going in or out too violently, was mentioned in the paper (page 125) as having been adopted about the year 1848 for the Sims compound engine at Lincoln. Some engines under his charge at the New River Water Works, which had been built by Boulton and Watt in 1812, and altered before 1850, had had those safety-catches fitted on them at the time of the alteration. Previously they had cataracts for controlling both the outdoor and the indoor stroke; that for the outdoor stroke was removed, and a safety-catch put on in its place. The man who came from Boulton and Watt to fit the catches did not quite know how to do it, and went down to the East London Water Works to see how it should be done; the safety-catches must therefore have been in regular use there at that time. There was also under his care an engine put up in 1824, and another in 1847, fitted with vacuum-vessels on the suction-pipes, exactly similar to that described in the papor (page 129); so it would appear that these devices were already in use before their adoption by the author.

With regard to the experience gained by the author from Cornish pumping engines at Grantham, Maidstone, and other places, which had convinced him that the cost of coals and repairs had been reduced to only one-sixth of the annual expenditure pertaining to. rotatory pumping engines previously in use there (page 130), it was difficult without seeing the actual figures to understand how such a conclusion could have been arrived at. Later on it appeared (page 131) that, while the rotatory ongine at Lincoln used 4 lbs. of coal per horse-power per hour, the Cornish engine used only $3 \cdot 14$ lbs.; but this was not even 25 per cent. difference, much less did it approach a saving of five-sixths. It would seem as though the rotatory pumping engines replaced by the author at the towns referred to must have been defective in their pump-valves, and must have been attended with considerable expense in consequence of 
(Mr. Edmund L. Morris.)

break-downs; otherwise he did not see how the expense could havo been so much more. From his experience he had found rotatory engines cheaper to work than Cornish. He considered Boulton and Watt engines better for pumping into mains than Cornish, on account of the former having only to pump against the actual head at any given time, instead of having-as was necessary in the case of the Cornish engine- to raise always a weight sufficient to overcome the greatest head, which might be required for only a portion of each day's work. But a direct-acting rotatory engine he thought was better than either, because, in addition to its greater economy ire working, it could generally be stopped before it sustained any damage when a burst occurred in the pumping main. A pair of singlecylinder rotative engines of 400 horse-power, erected at the New River Works over thirty years ago, which were very celebrated at the time, had had cylinders 60 inches diameter and 8 feet stroke, using steam of $40 \mathrm{lbs}$. pressure cut off at 1-14th of the stroke. It could be imagined at what a pace they would have come in, had it not been for the cranks and the fly-wheel, and what an enormous blow there must have been on the piston at the beginning of the stroke. The result had been that the crank shaft had gradually given way, and when taken out was found to be twisted like a bundle of sticks. The weight of the fly-wheel was excessive; and to this, coupled with the high initial blow of the steam in the cylinders, the failure of the shaft might no doubt be attributed. This instance showed that, apart from other reasons, it was not advisable to carry expansion too far in one cylinder. These cylinders were now being taken out, and the engines compounded, and fitted with a lighter fly-wheel and a starting engine; and very satisfactory results were anticipated from the alteration. Some compound engines erected at the same time as those just mentioned had worked well ever since; and in comparison with their horse-power had fly-wheels of half the weight that was at the time considered necessary for the singlecylinder engines. Instead of the quadruple-expansion engines that had been mentioned, he should himself prefer a triple-expansion engine with three bucket-and-plunger or piston-and-plunger pumps, which he believed would give a more favourable flow for the water. 
Mr. Edwand B. Marten, Member of Council, thought it was a very useful thing that when the Members went to the summer meetings of the Institution they were furnished at the time with descriptions of the works that were to be visited. It was the description so furnished of the Lincoln Water Works that had induced him to go and visit them on the occasion of the summer meeting there in 1885 ; and he had been surprised to find the sequence of the engines as they stood there, and could not quite see the reason of that sequence. He could understand well enough why the Sims engine had been difficult to pump with into the main, and why the author had subsequently adopted the rotatory pumping engine; but afterwards it did not seem. so clear why he should have reverted to the Cornish engine, with all the difficulties that were so well known to belong to it where the main was constantly subject to being drawn upon, in consequence of the reservoir being on the opposite side of the town to the engines. The present paper was the result of questions which he had asked after visiting the works, and which had elicited the interesting details and practical records so obligingly furnished by the author from his long and varied experience. He was glad to have in the paper so good an illustration and description of what a Cornish engine could do, and also what it could not do.

Mr. JoHN G. Marr thought the clearest statement that the Cornish engine was unfitted for pumping under varying pressures -as in cases where the service supplies were being drawn from the main-was to be found in a lecture by Sir Frederick Bramwell on the steam engine and its work: * in which it was said that, except for the purpose of pumping into a reservoir, where the head of water was nearly constant, and the engine was then in the same condition as in pumping from a deep well, he was of opinion that the employment of the Cornish engine for waterworks purposes was an entire mistake. In conformity with that opinion, he thought that, where the author had to pump into a main in which there was a varying pressure-as was evidenced by the fact that he had

* Science Lectures at South Kensington, vol. 1, 1878, page 154. 
(Mr. John G. Mair.)

to put a balance-valve to pump through, and that he was also obliged to put a throttle-valve into the equilibrium-pipe leading from the top to the bottom of the cylinder-it would have been better to adopt a different type of engine. But it appeared from the paper that his experience with the rotative engine had not been very satisfactory - a result totally different from the usual experience.

With regard to the quantity of feed-water used, it had been stated by Mr. Bryan that the Cornish engines at Old Ford used 21 lbs. of feed-water per indicated horse-power per hour; and Mr. Greaves' valuable paper read before the Institution twenty-five years ago (Proceedings 1862, page 157) gave 26 lbs. per hour, per horse-power measured in the main, as the amount of feed-water used by the Cornish engine pumping into the mains at old Ford over long periods of working, exclusive of the jacket condensation, which was returned by gravity to the boiler. A rotative engine doing the same work would use from 18 to $20 \mathrm{lbs}$. of feed-water per hour, per horse-power in the main: so that there was a saving of at least from 25 to 30 per cent. At the West Middlesex Water Works, where Cornish engines had been working for some time, three compound engines had lately been put up with $47 \frac{1}{2}$-inch cylinders and 8-feet stroke; and with each compound engine there was a saving in coals of about $£ 350$ a year over the consumption with the previous Cornish engines.

No doubt the Cornish engine was exceedingly valuable for pumping out a deep mine; but for surface pumping, especially for pumping into a main, it was better to pump with an engine that gave a more uniform flow. Any form of single-acting engine, used by itself alone for doing the work, gave necessarily an intermittent flow; and in such a case uniformity of flow must be made up simply by means of an air-vessel. Though not properly intermittent, the flow from a rotative engine was a varying one; the motion of the pump piston was exactly the same as the motion of the steam piston, and, both being controlled by the fly-wheel, the curve representing the velocity of flow was simply a curve of sines, as shown in Fig. 16, Plate 18. The only kind of engine that he knew of, which would deliver anything 
like a uniform flow of water, was that which had now been introduced into this country under the name of the Worthington engine, consisting of a pair of engines laid sido by side, in which the steamvalve of each in turn was actuated by its fellow. The flow of water coming from these engines was represented in Fig. 18, Plate 18, from which it would be seen that, when the flow from one engine was beginning to die away, the other engine took up its share of the work, and went on with it until its own turn came for dying away, when the first engine again followed suit; the moment the pressure in the main began to be relieved from one engine, the other engine went on again and maintained it. It was often alleged that two rotative engines coupled by cranks at right angles would give a uniform flow of water; but it would be seen from Fig. 17 that the mere superimposed reduplication thus obtained of the curve of flow from a single rotative engine (Fig. 16) simply gave a succession of humps of rather smaller magnitude for the double quantity of water delivered; and these inequalities had still to be taken up by the airvessel. The Worthington engine he had seen purnping through 30 miles of main, where the friction alone amounted to $1000 \mathrm{lbs}$. per square inch on the pump. Now if the flow of water were to vary at all in so long a main, considering that nearly the whole pressure was due to friction, the slightest increase in speed would cause the pressure to increase to such an extent that the result would be to burst the mains; and this was exactly what had been found to be the case, when engines of other types than the Worthington had been used.

Mr. HenRx Davex, in connection with the uniform flow of water through a main from a pumping engine, referred to the pair of pumping engines he had put up thirteen years ago at the Clay Cross colliery near Chesterfield, which were placed at the bottom of the Morton pit for forcing water in one direct lift of 950 feet to the surface (Proceedings 1874, page 270). Those engines had been working almost night and day from that time to the present. The theory that he had advanced in connection with them to the late Mr. Howe, the engineer of the colliery, was that without any air- 
(Mr. Henry Davey.)

vessel they would deliver a uniform flow of water through the main to the surface, provided they were not coupled in any way whatever beyond merely delivering into the main at the same level; and they had been found to do exactly as predicted. They were in fact directacting steam-pumps; their valve-gears were not coupled in any way whatever, but they were left free to take what course they chose; there was a separate steam stop-valve for each engine. At first the engines began to work as if they hesitated about it, but they soon took up a motion following the line of least resistance, and so fell into a way of working which gave a perfectly uniform flow. It was easily seen why it should be so: both pistons were exposed to the same steam-pressure, and if one engine moved a good deal faster than the other it imposed an extra resistance on the second engine, which consequently lagged; and so, left to themselves, of their own free will they took the line of least resistance. The second engine began to move before the first engine had completed its stroke; and the action described as produced by the Worthington engine was obtained without any coupling of the valve-genrs. The result would not be so perfect with an air-vessel; and in his own practice in putting pumping engines underground to force the water to the surface he had never used air-vessels, except in the case of rotative engines.

The President was sure the Members would join with him, not only in passing a vote of thanks to the author, but also in regretting that he was prevented by illness from being present. In his unavoidable absence he was very glad that the engineers of some of the extensive waterworks in London had been able to come and join in the discussion. He had great pleasure in proposing a hearty vote of thanks to $\mathrm{Mr}$. Teague for his interesting paper.

Mr. Henry J. MaRTen wrote that from the statements given in the paper (page 130) he inferred that the rotatory pumping engines which the author had replaced by Cornish engines with so great an economy 
in fuel and repairs must have been of a very inferior kind, and certainly not fairly comparable with properly constructed rotatory engines such as those turned out by the best makers. In his own experience he had found only a very slight difference in the duty performed by the two classes of engines; and his preference for either one or the other was guided by the special circumstances connected with each case.

With regard to the combined bucket and plunger pump mentioned (page 126) as having been applied by the author to an auxiliary engine at Lincoln in 1852, it was a curious coincidence that in the same year a pump of that description had been constructed for the Bridgnorth Corporation Water Works by himself and his brother, Mr. Edward B. Marten, having been designed by them about a year previously. The idea, as in Mr. Teague's case, had been taken from the little lift-pump sketched in Smeaton's experimental enquiry into water wheels, in which the area of the pump-rod was shown to be half that of the bucket, with the object of securing uniform delivery from the pump spout over the model water-wheel. By allowing the half-area rod to work through a stuffing-box in a close lid fitted over the lift-pump barrel, the uniform-throwing lift-pump was converted into the uniform-throwing force-pump, now in everyday use and known as the combined bucket-and-plunger pump.

Mr. JoHN W. Gray, engineer of the Birmingham Water Works, wrote that he had not found any pumping engine yet to come at all near to a genuine Cornish engine for economy in working, taking all the year round. As for a six hours' trial or any sort of racing, he did not believe in the results so obtained. The pumping engines at Whitacre, near Birmingham, were compound high and low pressure; the advantage of a double-acting Cornish engine was thereby obtained. The load was the same as in a single-acting Cornish engine; the steam worked expansively on the load, in a similar manner to a Cornish engine. Rotatory engines he considered were not to be compared with Cornish, or with a compound such as now described. An advantage of the compound over the Cornish was that a greater quantity of water was raised by the same weight of 
(Mr. John W. Gray.)

engine; and also the expansion was not so sudden, and was therefore less straining to the machine. The differential gear was a great improvement for both Cornish and compound, and the cut-off was beautifully arranged by that means.

Mr. William Vawdrey, engineer of the South Staffordshire Water Works, wrote that, although he had a decided partiality for Cornish pumping engines, he had never found them so much more economical in their working as the author appeared to have done; and be could only suppose that the rotatory engines with which the comparison mentioned in the paper had been made had not been in as good working order as the new Cornish engines by which they had been superseded. Although he did find the Cornish engines work cheaper in regard to fuel than the fly-wheel and double-acting engines, yet there was not such a large difference. These remarks referred simply to coal, otherwise steam; but as regarded oil \&c. and renewals, he had no doubt that a Cornish engine, well erected and with its gears well balanced, would be found, as the author snid he had found it, much the most economical class of pumping engine; and in cases similar to that dealt with at Lincoln, where the engine was working direct into the supply main, it was in his opinion much safer than a rotatory engine. For eight years he had had a Cornish engine supplying a district direct, without a reservoir or tank or any outlets whatever beyond the consumers' draw-taps; it was kept at work night and day, and pumped at various speeds between half a million and a million gallons a day under a head of 220 feet or 95 lbs. per square inch; and during the whole time there had been no trouble or accident of any kind. During that period of eight years, nearly the entire cost of the engine had been saved in the cheaper pumping of the water, as compared with what it had previously cost when two 50 H.P. high-pressure horizontal engines had been employed for doing the same work, but pumping under a fixed head into a reservoir. In all the Cornish engines which he had had erected, safety catches as described in the paper were fitted on the gear shafts, thereby reducing to a minimum the chances of much damnge arising in case of a main bursting into which the engines 
were working; whereas in the fly-wheel engines, unless very sensitive governors were provided, great damage was generally done in such a case, if the engine-man did not fortunately happen to be near the gear at the moment of the accident occurring.

Mr. Teague wrote in reply that he had not found the intermittent action of the Cornish engine, when pumping direct into the main with an air-vessel of the proper size and properly charged, to vary more, even under a pressure of 350 feet head of water, than from 6 to 10 feet of head; and when the water was being pumped direct into a reservoir, not the slightest variation was perceptible at the delivery end. Instances had been met with where the variation had been as great as 40 feet, but where complete satisfaction had nevertheless been felt that all was right. The Cornish engine had not been found by himself to require constant attendance; it worked for hours without alteration, except in case of a main bursting, or the sudden opening of a hydrant, and even in such cases it was stopped by the safety-catches. In his own experience it had proved quite as safe as the rotatory engine, if not safer; and the difference of pressure consequent upon the constant draw-off from the delivery main was but slightly felt.

With respect to the rotatory engines which he had replaced by Cornish (page 130), had they not in his own opinion been defective he should not have advised their discontinuance. At Lincoln however the difference in coal consumption between the Cornish and the rotatory engine had not been found greater than stated in the paper (page 131); and if both engines had been started new together, the difference would no doubt have been even less.

A few hours' test he quite agreed was not to be relied on; and those, who like himself/could remember the excitement that prevailed from fifty-five to sixty years ago respecting the duty of engines, did not care much for such short trials.

The results mentioned in page 130 were not given as representing a comparison between good Cornish and good rotatory engines; but to show the great loss that had been occurring with some engines in actual use, which had previously been held in very good estimation 
(Mr. Teague.)

by others than himself. He should be sorry for it to be though that he undervalued the rotatory engine; there were places where hi had used it in preference to the Cornish, and others where he hac preferred the direct-acting Tangye engine to either. But where the situation would admit, and looking at the yearly cost of repairs: lubricants, coals, \&c., he greatly inclined towards the Cornish engine: especially as he had not found the rotatory engine to be attended by the great benefit and saving which were said to be derived from its use in connection with a variable head.

In 1843, while he was in charge of the Bowden Hill manganese mine, about a mile northwest of Brent Tor near Tavistock, one of the Sims compound rotatory engines, which had cylinders without steam-jackets, was used both for pumping and for winding. The empty skip was lowered to a depth of 40 fathoms by a brake on the winding drum. When full it contained $6 \mathrm{cwts}$, in addition to its own weight and that of the chain; and the number of skip-loads raised was at the rate of ten per hour. When starting to wind this load, the boiler steam was each time admitted direct into the lowpressure cylinder for a few strokes; and the consequence was that, after the skip had been wound to surface, the steam required for pumping alone was found to be less than in the ordinary continuous pumping when no winding had to be done. For ascertaining the coal consumption during the eight hours of winding as well as pumping in each day and also during the sixteen hours of pumping alone, the coal was weighed during the two periods, and the difference per hour was found to be but small, whether pumping alone or winding as well. No doubt the explanation was that much of the heat absorbed from the boiler steam by the low-pressurc cylinder and its surroundings was given off again afterwards in the intervals when working compound; and also that the friction in the low-pressure cylinder was reduced during the time that the direct supply of boiler steam was continued.

In an instance that had occurred a short time ago, where there was a good single-cylinder rotatory engine and it was found desirable to increase the pumping power, it had been decided to replace it by a compound engine, which it was thought would be attended with a 
great saving of coal \&e. The result of twelve months' working however had shown that but little saving had been realised.

Just as the Cornish and rotatory and other engines were severally suited for different kinds of work, and the same kind of engine was not the one for every position, so was it also with the invaluable Harvey and West double-beat elack. There were places where it was not applicable, and where the leather clack was the one more suitable. In such cases the break-clack described in the paper was of value and much used.

To a three-throw pump he presumed no one would think of fixing a vacuum vessel: although it might even there be of advantage at starting. The benefit or otherwise would be easily seen by fixing a gauge on the suction-pipe.

The cylinders of the Cornish engines referred to in the paper were without steam-jackets. 
LINCOLN WATERWORKS ENGINES. Plate 14.

Fig. 1.

Sims' Original

Compound Engine.

Cornwall 1836.

Lincoln 1848.

Scate $1 / 150^{\text {the }}$
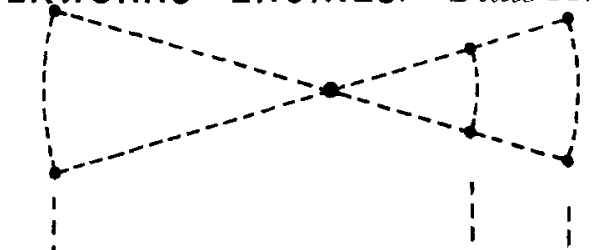

Fig. 2.

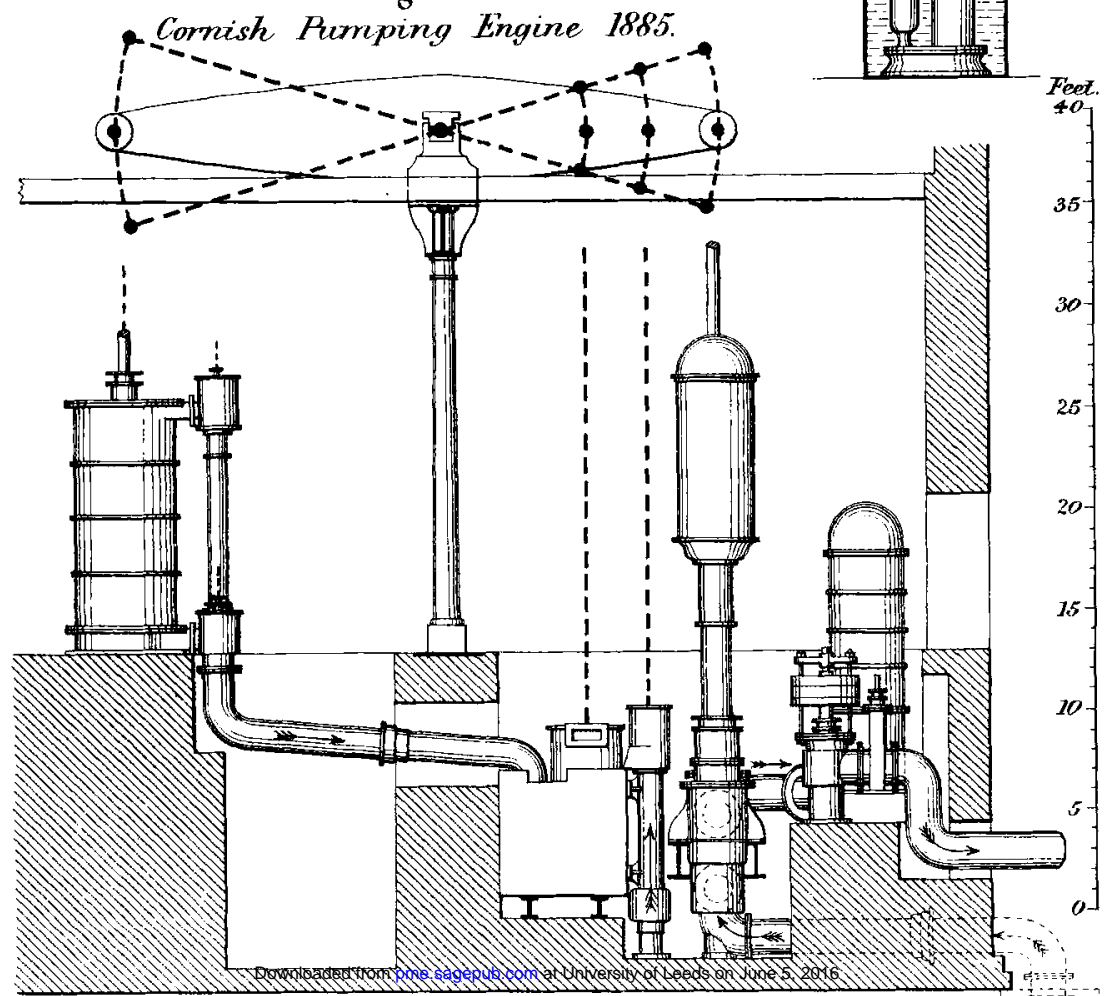


LINCOLN WATERWORKS ENGINES. Plate 15.

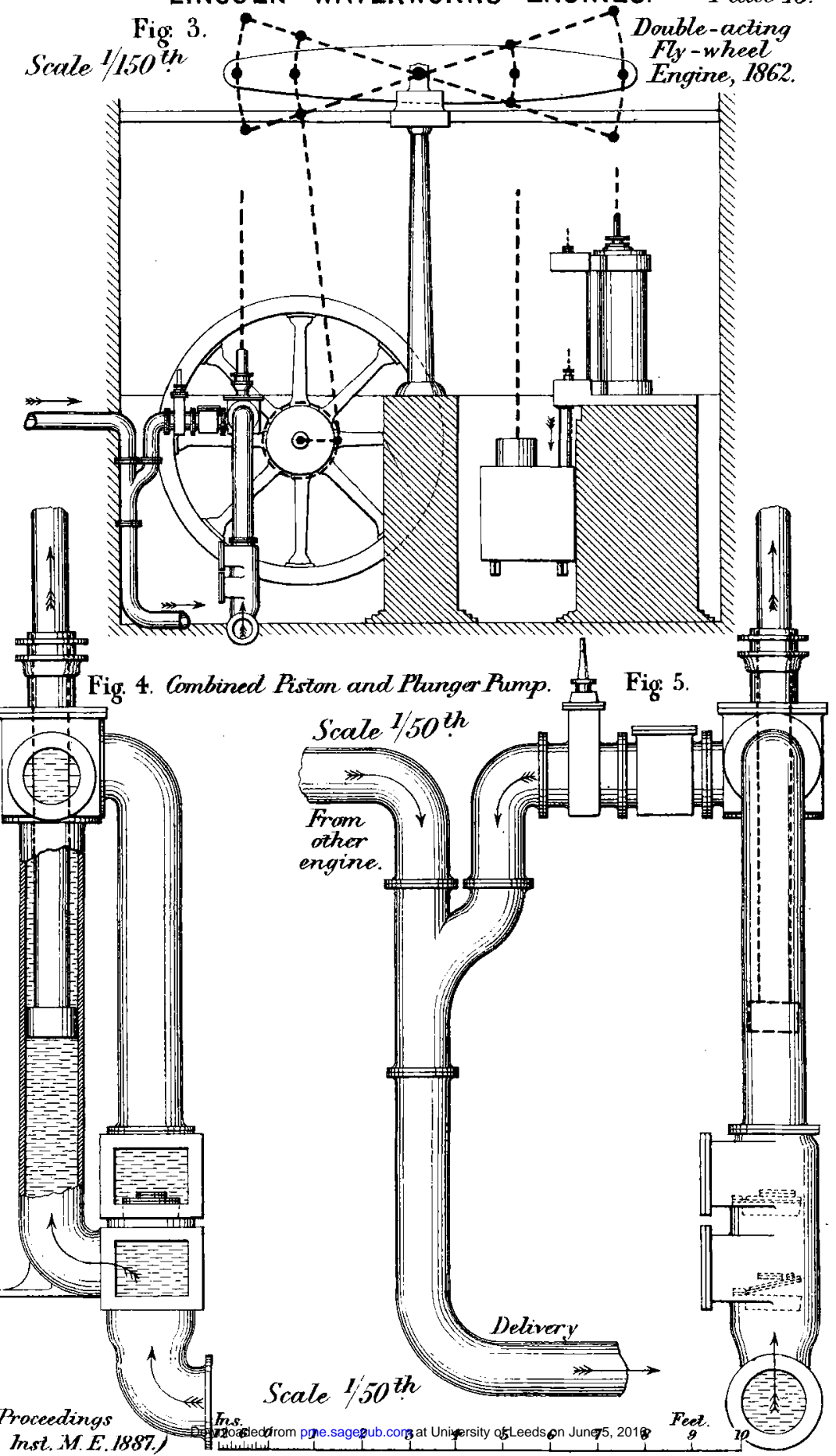


LINCOLN WATERWORKS ENGINES. Plate.16.

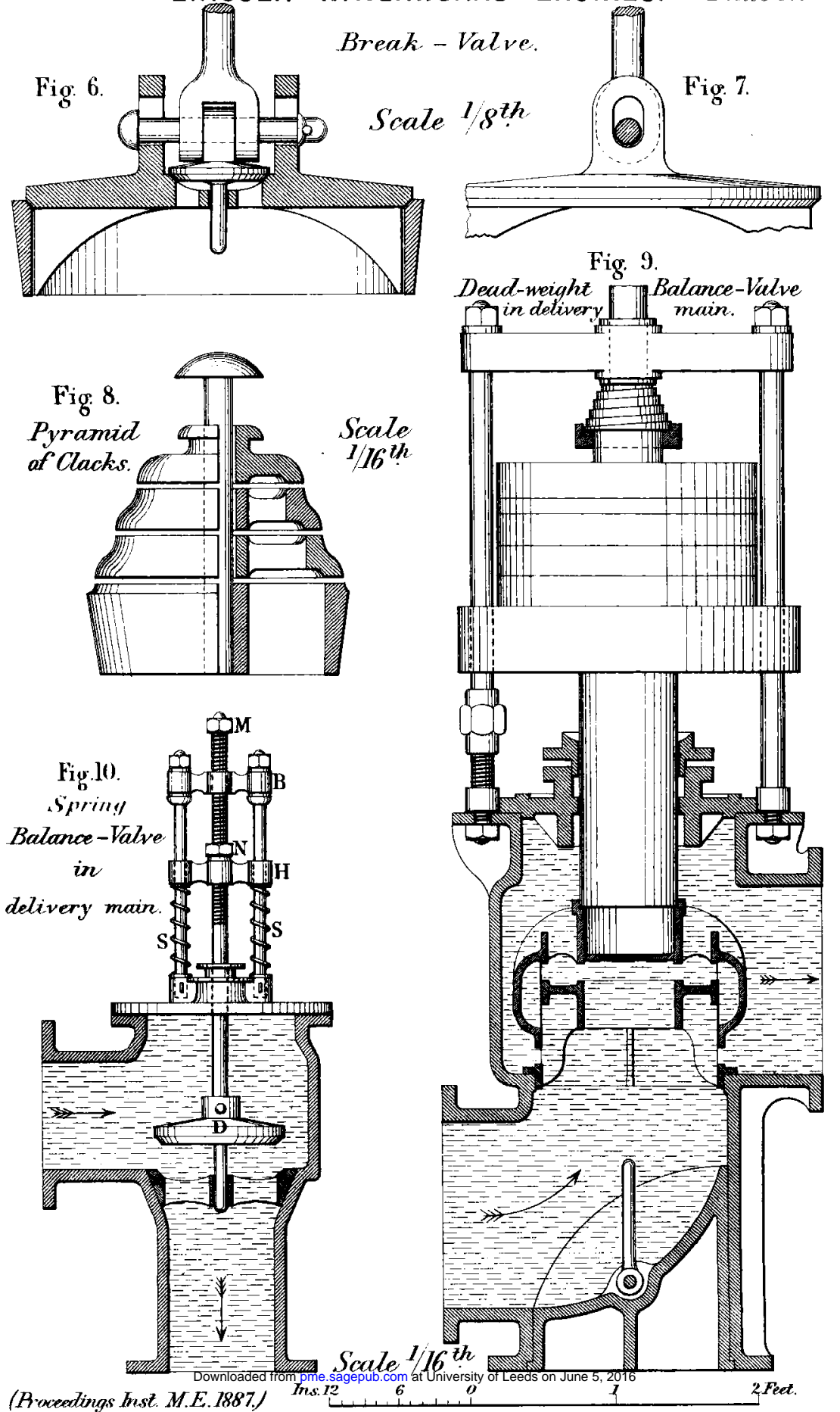


LINCOLN WATERWORKS ENGINES. Plate 17.

Exhaust and Egaitibrium

Valve-Catches,

and Check Throttle-Valve.

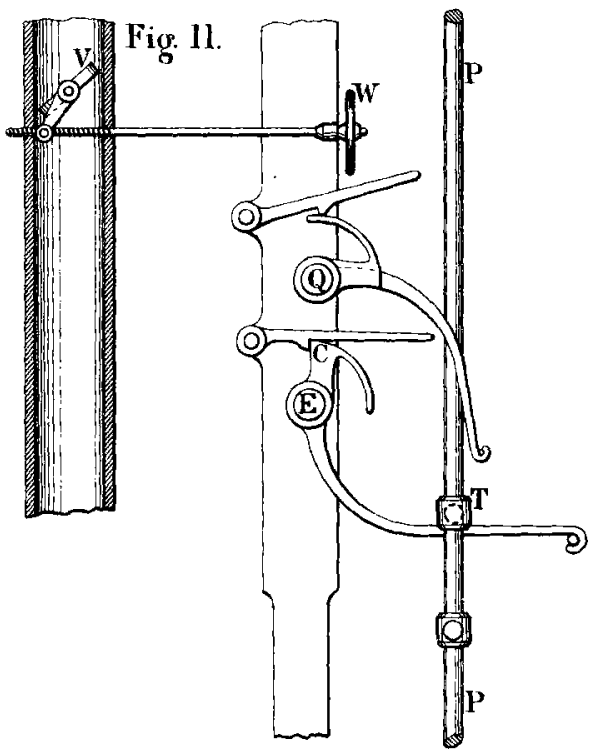

Preak Clack.

Scale $1 / 16^{\text {the }}$

Fig. 12. Section.

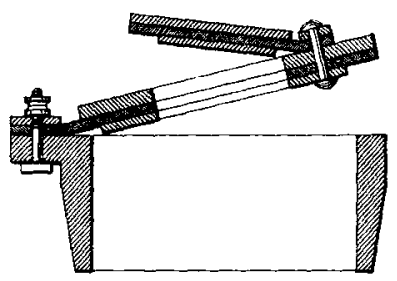

Fig. 13. Plan.

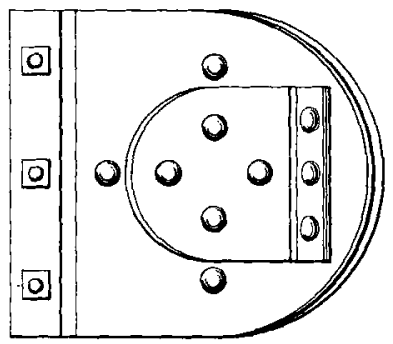

Indicator Diagrams showing vacuum above and below Foot Valve.
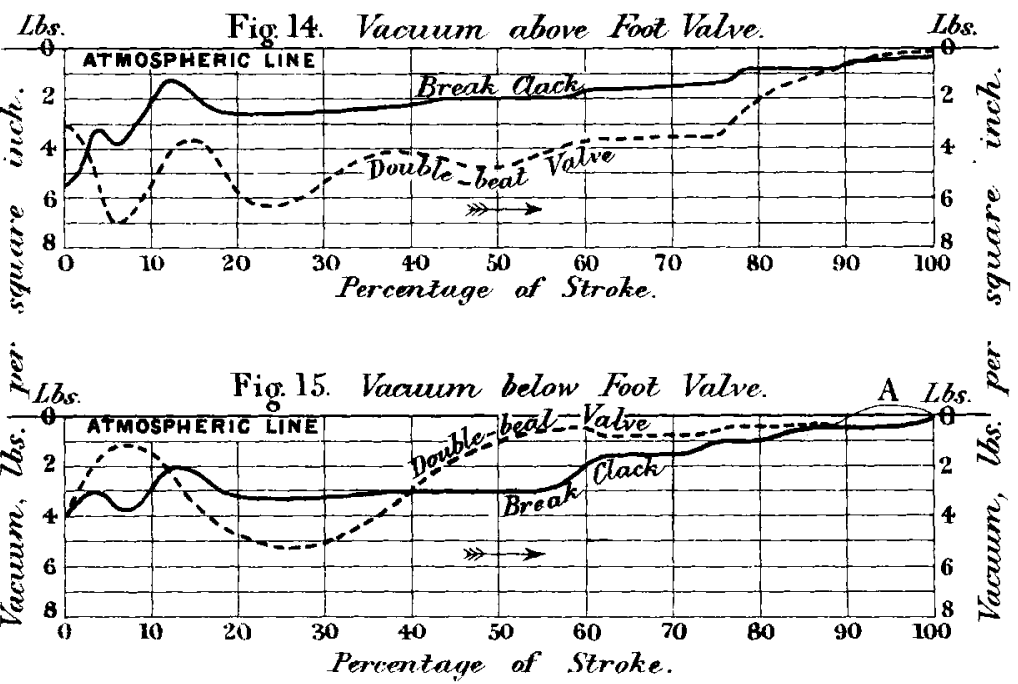

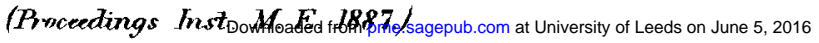




\section{PUMPING ENGINES.}

Fig: 16. Velocity of Flow

from Double-acting Pump

worked by croonk.

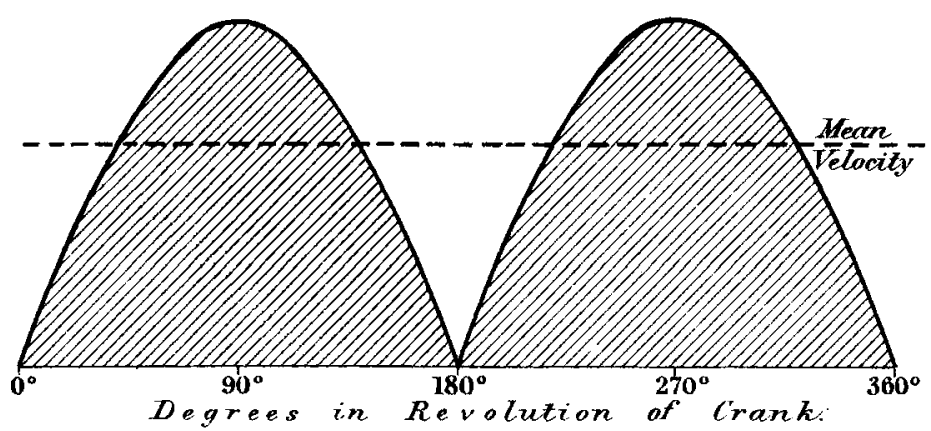

Fig 18. Velocity of Flow
Fig. 17. Velocity of Flow from two Double-acting Aumps worked by cranks at right angles.

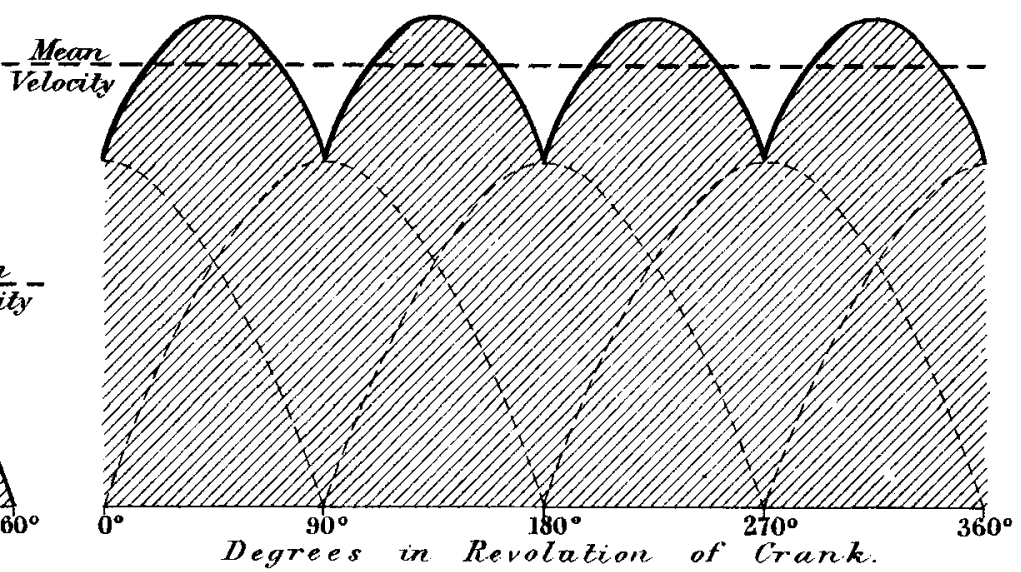

from Worthington Pumping Engines.

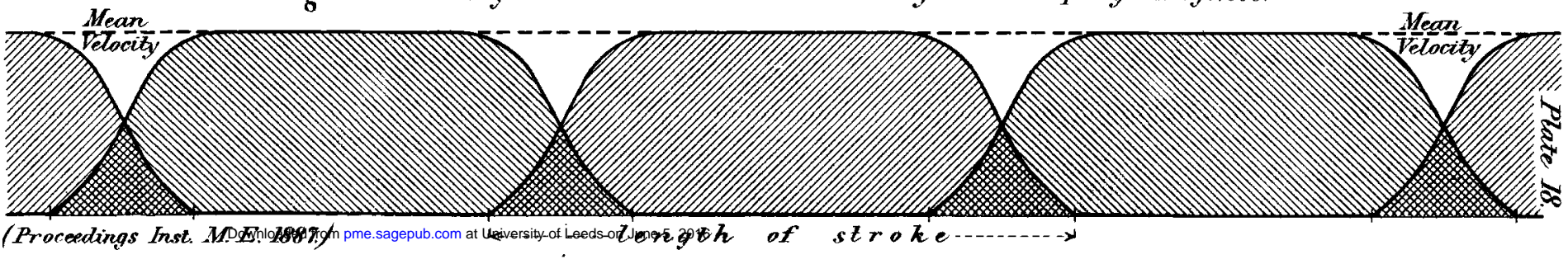

